\title{
An Interesting Case of a Butcher Who Attempted to Cut His Neck
}

\author{
N R Ankale, ${ }^{1}$ R S Mudhol, ${ }^{2}$ Rajesh Radhakrishna Havaldar, ${ }^{1}$ Anju Singh ${ }^{1}$
}

Introduction

\section{$\underline{\text { ABSTRACT }}$}

Cut throat injuries are well recognized in homicide but less recognized in suicides. The incidence of suicide is increasing worldwide owing to the more stressful strenuous lifestyle and other risk factors like substance abuse. Suicide by incising one's own throat is associated with hesitation marks whereas homicidal wounds are not.

Case Report

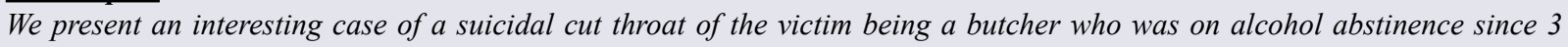
days with severe injuries of supraglottic larynx and cricopharynx, surprisingly without any evidence of hesitation marks. He underwent immediate neck exploration and suturing of the injured structures without the need of a tracheostomy.

Discussion

A multidisciplinary approach by Otolaryngologists, Psychiatrists, Intensivists, and Anaesthetists is required in the effective management of these victims. A thorough proper early assessment can totally avoid the need of tracheostomy which is recommended in practice, hence preventing complications arising out of this unnecessary but advocated procedure..

$\underline{\text { Keywords }}$

Neck Injuries; Suicide; Treatment Outcome

$O$ uicide is an act of taking one's life. Cut throat injuries are defined as incised injuries or those resembling incised injuries in the neck, inflicted by sharp objects. In the present scenario, the incidence of suicide is gradually increased worldwide owing to the more stressful strenuous lifestyle and other risk factors like substance abuse. This may result from accident/ suicide/ homicide and they are potentially life-threatening as many vital structures are present in this area.

\section{Case Report}

42 year old male butcher presented to the casualty with lacerated cut wound in the neck allegedly using a butcher's knife.

He was a chronic alcoholic since 15 years abstaining for past 3 days.

He was semiconscious, afebrile having tachycardia and was intubated in the casualty through the neck wound. (Fig. 1)

The neck had a laceration of about $7-8 \mathrm{~cm}$, clean, with extensive soft tissue injury and haemorrhage with exposed thyroid and epiglottic cartilage. No other injuries were noted. Surprisingly, no hesitation marks/ scars were present. (Fig. 2)

Patient was HBsAg positive. His preoperative haemoglobin was low, hence intraoperative blood transfusion was given.

On table, nasotracheal intubation was performed and a nasogastric tube was passed. Then the neck could be adequately exposed for repair. Intraoperatively, injury to the right lamina of thyroid cartilage, tear in anterior wall of cricopharynx, and a full thickness horizontal cut in the epiglottis was noted. Extensive tears in platysma, sternoscleidomastoid and infrahyoid muscles at the level of the thyroid cartilage were seen. (Fig. 3) Hence it was

1 - Department of ENT, Jawaharlal Nehru Medical College
KLE University, Belagavi, Karnataka
2 - Unit Chief and Vice Principal
Jawaharlal Nehru Medical College
KLE University, Belagavi, Karnataka
Corresponding author:
Dr Rajesh Radhakrishna Havaldar
email: rajeshhavaldar@yahoo.com
KLE University, Belagavi, Karnataka

2 - Unit Chief and Vice Principal

Jawaharlal Nehru Medical College

Corresponding author:

email: rajeshhavaldar@yahoo.com 


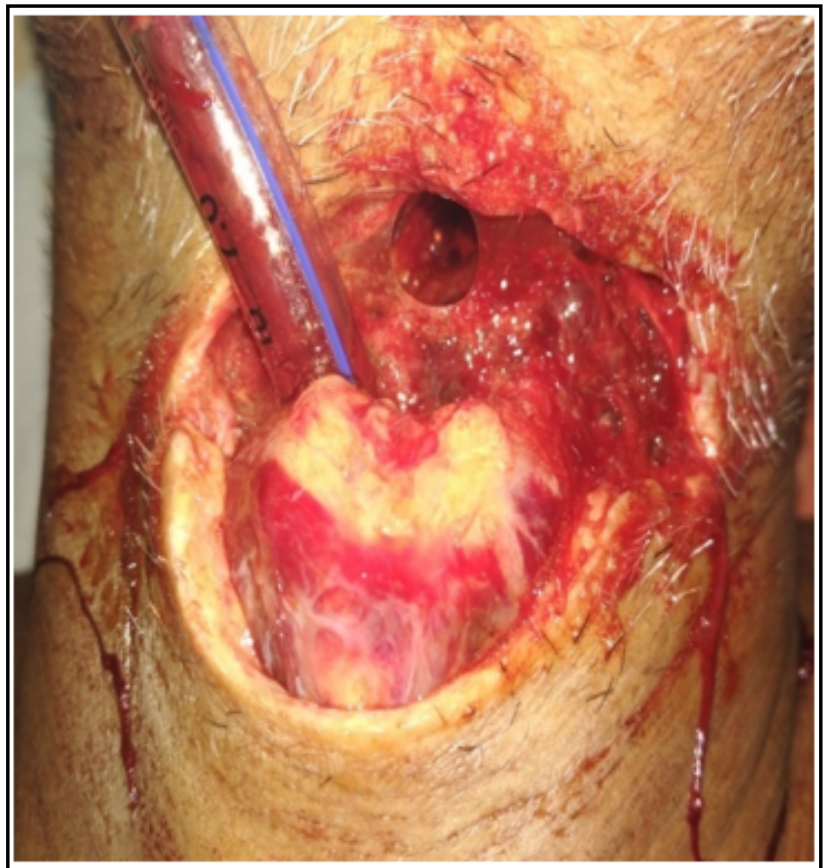

Fig. 1. Intubation through the neck wound

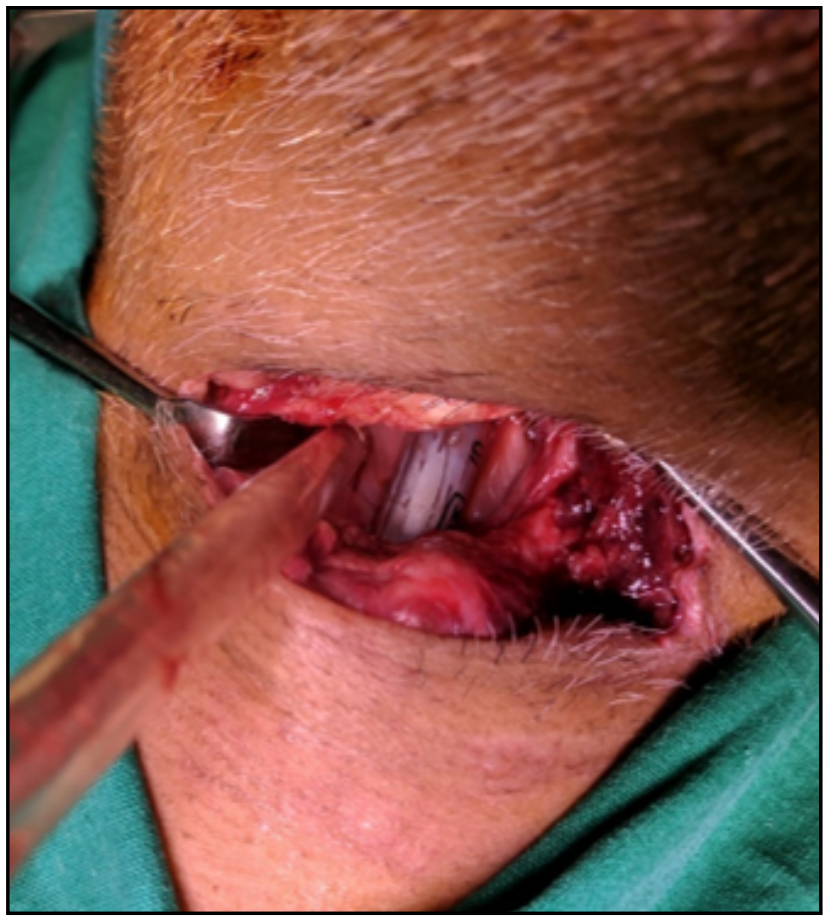

Fig. 3. The soft tissue injuries

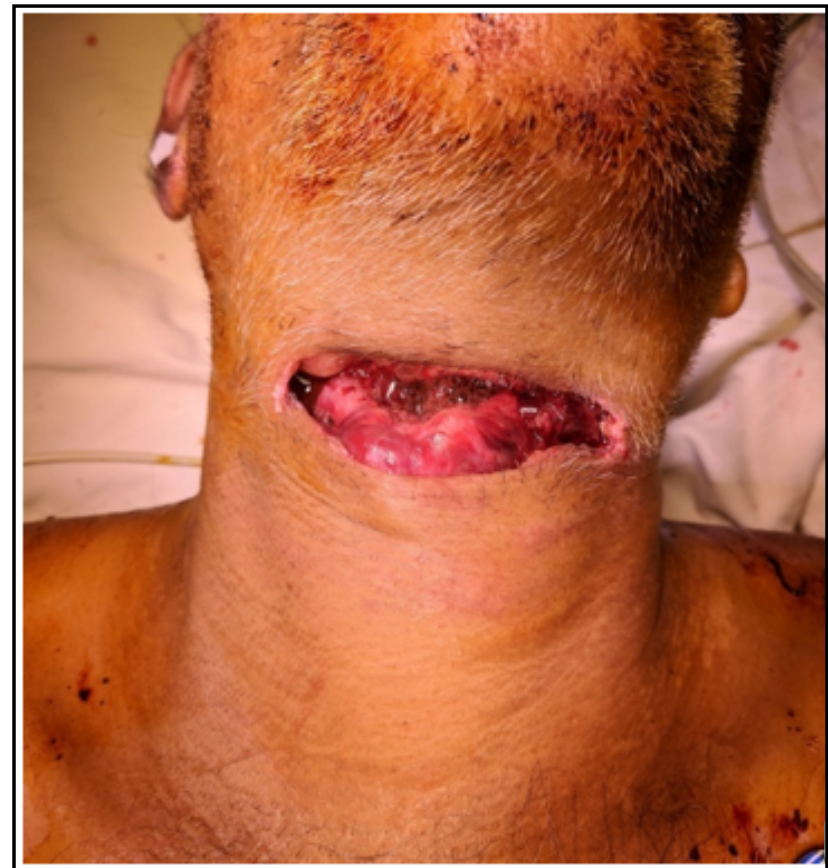

Fig. 2. Cut throat without hesitation marks

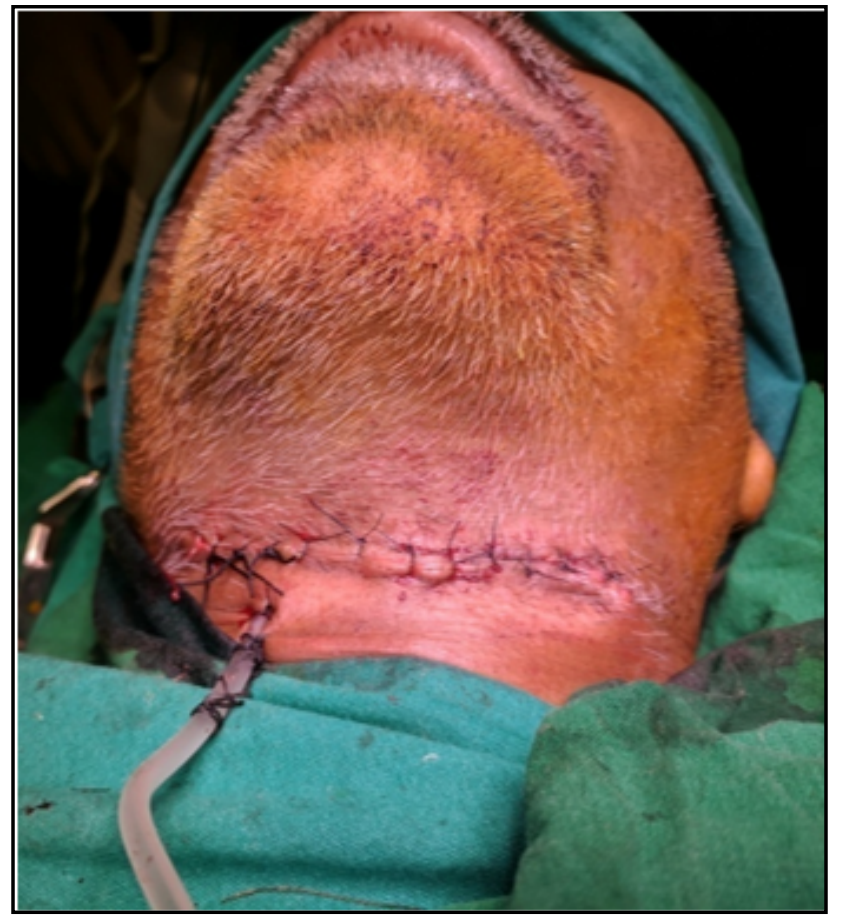

Fig. 4. Immediate post-operative photograph 
in zone II of neck injuries (Roon and Christensen's classification).

The wound was washed thoroughly with povidone iodine and hydrogen peroxide. Suturing was done for each anatomical structure in layers after debriding the exposed cartilage. The vocal cords were visualised and found to be intact. The perichondrium of the thryroid cartilage and epiglottis were sutured respectively. Subsequently, cricopharynx was repaired in layers for the mucosa, muscle and perichondrium. Carotid artery was unaffected bilaterally. Bleeding left superior thyroid vein was ligated. Minor bleeders in the neck were cauterised. The external laryngeal nerve was unexposed in the surgical field. Hemostasis was achieved and neck drain was inserted. Soft tissue, subcutaneous tissues and skin were closed in layers using 3-0 polyglactin (Vicryl ${ }^{\circledR}$ ) and 4-0 monofilament nylon (Ethilon ${ }^{\circledR}$ ) respectively. (Fig. 4)

Postoperatively, the patient maintained saturation well without any oxygen/ external support. The patient pulled his nasogastric tube spontaneously in the postoperative period, hence had to be kept on IV fluids and Total Pareneteral Nutrition by the Intensivist. $\mathrm{He}$ was monitored closely in the ICU and anti-suicidal measures were taken along with injections containing Calcium Pantothenate, Cyanocobalamin, Nicotinamide, Pyridoxine, Riboflavin, and Thiamine as active ingredients and injection haloperidol $5 \mathrm{mg}$ every 8th hourly as per Psychiatrist's advice. He was started on Injection Meropenem, Sulbactum for 5 days followed by Injection Amoxycillin-Clavulanate for 10 days. Gastroenterology, Neurology and Neurosurgery opinion was sought and was managed conservatively.

On postoperative day 3 , drain was removed and on day 5 , he was extubated successfully. He had a good cough reflex and voice quality. Nasogastric Tube was inserted using direct laryngoscope and feeds and medications were continued as per psychiatrist and dietician.

On postoperative day 8 he underwent suture removal and wound was healthy. He underwent daily compression dressings of the neck till postoperative day 14 .

On postoperative day 14 the nasogastric tube was removed and the patient was started on sterile water and clear liquids.
He was started on soft diet from post op day 15 The postoperative period was uneventful and he was discharged.(Fig. 5)

\section{Discussion}

Suicide is one of the ten leading causes of death in the world with about one million deaths recorded annually. ${ }^{1}$ After a thorough literature search using PubMed, EMBASE, Google Scholar, we came to a conclusion that cut throat injuries are less commonly reported in literature and suicidal cut throat injuries are very rare. No clear incidence rate has been documented anywhere. Often it is committed by individuals suffering from a mental illness; therefore it can be used as an index of mental health in a community. ${ }^{2}$ The socio demographic factors are of particular interest in this case as it has been seen according to a study done by De et al that males accounted for about $86.06 \%$ of the cases. ${ }^{3}$ People coming under the non-waged workers group are more commonly affected. ${ }^{4}$ This is more commonly observed amongst the males since they are the breadwinners in most of the families. They tend to get mentally affected

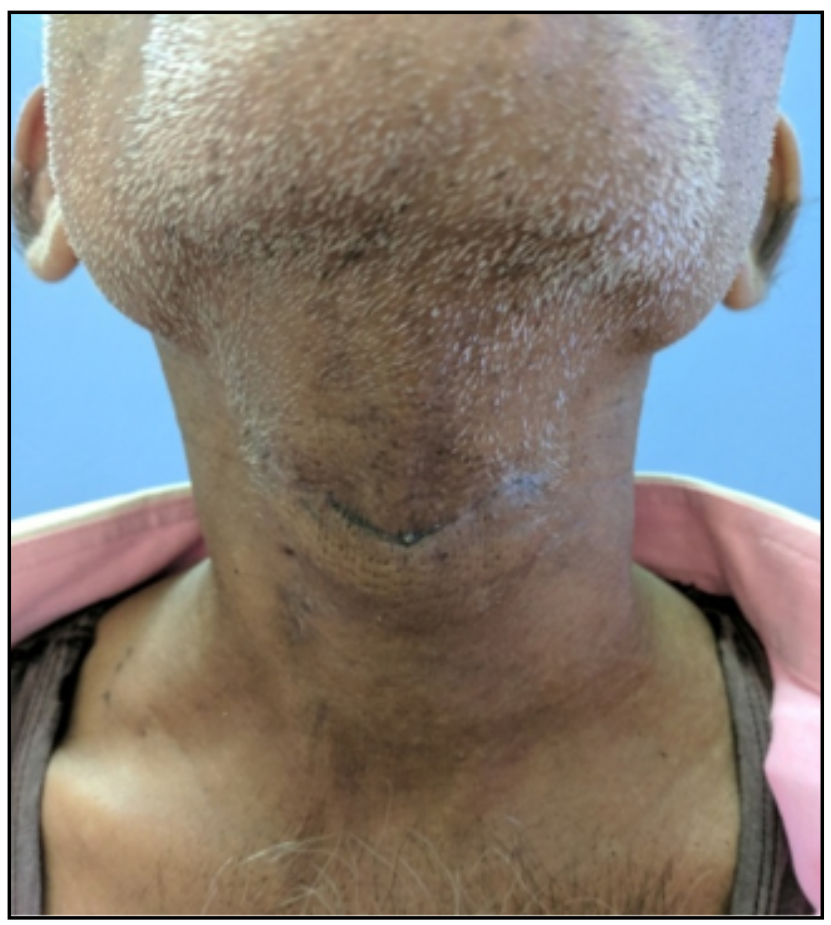

Fig. 5. The wound healed uneventfully 
when they are not able to make both ends meet and that provokes them to take the extreme step. ${ }^{5}$ Alcohol consumption as seen in our case is also a prevalent factor and the ease of availability of the weapon such as rope, knife or gun acts as a catalyst in accelerating the process of being a victim to suicide. ${ }^{2}$

When suicidal cut throat injuries occur, a collective effort from the Otolaryngologist, Anaesthesiologist, Intensivist and Psychiatrist is needed to obtain a successful outcome. ${ }^{6}$

Neck is a Pandora's box with many structures like neurovascular bundles, larynx, trachea, esophagus and the spinal cord. Injury to any of these structures leads to life threatening emergencies for the otolaryngologists. The injuries are varied and depend upon the pattern, site, and depth of the cut on the neck. ${ }^{2}$

According to Roon and Christensen's classification, ${ }^{7}$ neck injuries are divided into 3 anatomical zones:

Zone I - area between the clavicles and the inferior margin of cricoid cartilage. Structures include vertebral and proximal carotid arteries, major thoracic vessels, superior mediastinum, lungs, esophagus, trachea, thoracic duct and spinal cord.

Zone II - area from the inferior margin of cricoid cartilage to the angle of mandible. The carotid and vertebral arteries, jugular veins, esophagus, trachea, larynx and spinal cord are found in this zone.

Zone III - area located between the angle of the mandible and the base of the skull. It includes the carotid and vertebral arteries, pharynx and spinal cord.

Unlike Zone II, Zones I and III are protected by bony structures making Zone II more vulnerable to injuries. Most of the zone II injuries are associated with laryngeal injures which was present in this case as well.

In this case that we are reporting, as soon as the victim arrived at the casualty, the anaesthesiologist secured the airway, the otorhinolaryngologist assessed the injury and surgically repaired the severed tissues with the aim of restoration of breathing, swallowing and phonation and the psychiatrist along with intensivist provided adequate care and supervision. This is consistent with what has been advocated by Adoga. ${ }^{2}$

While securing an airway, orotracheal intubation is preferred ideally in the awake patient which is followed by the insertion of a tracheostomy tube through the transected portion of the trachea if a transection is present. Few are of the opinion that this could be dangerous as it can damage the already injured larynx or increase the chances of aspirating vomitus, blood or secretions. ${ }^{8}$ There are also reports that in severe airway compromise, the use of flexible fibreoptic laryngoscope to intubate the trachea following a cut throat injury can be done ${ }^{9}$ but in our case a gentle attempt to insert the tube through the orotracheal route was done with minimal manouvering from the external neck wound.

Zone II injuries are usually easily managed with neck extension provided there is no contraindication. ${ }^{10}$

According to Iseh K.R et al, pharyngeal, hypopharyngeal and laryngeal mucosal lacerations should be repaired within 24 hours. ${ }^{11-13}$ This patient presented to us within 6 hours and hence the outcome was better after primary repair, as the time elapsed before repair of layngeal mucosal lacerations has an effect on both airway stenosis and on voice restoration, ${ }^{14}$ hence an additional procedure of tracheostomy which is advocated by many was avoided successfully.

Pharyngocutaneous fistula is a feared complication in such a situation. Care must be taken to prevent this complication while carrying out pharyngeal/ hypopharyngeal repair. This needs good knowledge of the anatomy of the neck and meticulous approximation of tissues and the use of a nasogastric tube as was inserted in our case, so as to avoid oral feeding for a period of 7-10 days. ${ }^{2}$

Above all, we need to focus on the prime motive of the patient which leads to this state. Mental health intervention by identifying the disorders like depression, substance abuse which was alcohol dependence in our case, schizophrenia etc. needs to be addressed appropriately.

Even after discharge from otorhinolaryngological care, individuals should be closely followed and supervised in order to prevent another attempt which may lead to death in approximately $25 \%$ cases according to a study done by Amadasun. ${ }^{15}$

\section{Conclusion}


Suicidal cut throat injuries account for a sizeable number of deaths and hence is an important cause of morbidity and mortality. A thorough proper early assessment can totally avoid the need of tracheostomy which is recommended in practice, hence preventing complications arising out of this unnecessary but advocated procedure. Such injuries can be managed adequately with the help of endotracheal intubation reserving tracheostomy only in case of dire emergencies. This case demonstrates the importance of early presentation, immediate and timely management by the intensivist, anaesthesiologist and the otolaryngologist in close collaboration with the psychiatrist to offer a successful outcome to the patient and also the need to promptly identify the triggering factor for the condition and address the same.

\section{References}

1. Nock MK, Hwang I, Sampson N, Kessler RC, Angermeyer M, Beautrais A, et al. Cross-National Analysis of the Associations among Mental Disorders and Suicidal Behavior: Findings from the WHO World Mental Health Surveys. PLoS Med. 2009; 6(8): e1000123. https://doi.org/10.1371/journal.pmed.1000123

2. Adeyi AA. Suicidal Cut Throat Injuries: Management Modalities, Mental Illnesses - Understanding, Prediction and Control. Ed. Prof. Luciano LAbate. 2012. ISBN: 978-953-307662-1, InTech, Available from: http://www.intechopen.com/ books/mental-illnesses-understanding-prediction-and-control/ suicidal-cutthroat-injuries-management-modalities

3. De S, Sarma M.K. Cut throat injuries at a tertiary referral hospital in Guwahati: a review of 165 cases.IOSR Journal of Dental and Medical Sciences (IOSR-JDMS). 2016,15(8):36-41

4. Gallagher LM, Kliem C, Beautrais AL, Stallones L. Suicide and occupation in New Zealand, 2001-2005. Int J Occup Environ Health 2008; 14(1): 45-50

5. Adoga AA, Ma'an ND, Embu HY, Obindo TJ. Management of suicidal cut throat injuries in a developing nation: Three case reports. Cases J. 2010; 3:65

6. Herzog M, Hoppe F, Baier G, Dieler R. Injuries of the head and neck in suicidal intention. Laryngorhinootologie 2005; 84(3):176-81

7. Fagan JJ, Nicol AJ. Neck Trauma. In: Gleeson, M., Ed., ScottBrown's Otorhinolaryngology, Head and Neck Surgery 2008; 7th Edition, Great Britain, Hodder Arnold, 1768

8. Schaefer SD, Close LG. Acute management of laryngeal trauma. Update. Ann Otol Rhinol Laryngol. 1989; 98: 98-104

9. Venkatachalam SG, Palaniswamy Selvaraj DA, Rangarajan M, Mani K, Palanivelu C. An unusual case of penetrating tracheal ("cut throat") injury due to chain snatching: the ideal airway management. Indian J Crit Care Med. 2007; 11(3): 151-4

10. Manickam A, Sengupta S, Sannigrahi R, Saha J, Basu SK, Ray S. Self inflicted cut throat injury - A series of 2 cases. Global Journal of Medical Research 2015; S 1

11. Onotai, LO, Ibekwe U. The Pattern of Cut Throat Injuries in the University of Port-Harcourt Teaching Hospital, Portharcourt. Nigerian Medical Journal 2010; 19: 264-6

12. Iseh, KR, Obembe A. Anterior neck injuries presenting as cut throat emergencies in a tertiary health institution in North Western Nigeria. Nigerian Medical Journal 2011; 20:475-8

13. Kendall, JL, Anglin D, Demetriades D. Penetrating neck trauma. Emergency Medicine Clinics of North America 1998; 16:85-105

14. Leopold DA: Laryngeal trauma, Arch Otolaryngol. 1983; 109:106-9

15. Amadasun JEO. Decision making in self inflicted life threatening neck injuries report of two cases. J Otorhinolaryngol Head Neck Surg. 1999; 2: 21-3. 